\title{
Callibrachion and Datheosaurus, two historical and previously mistaken basal caseasaurian synapsids from Europe
}

Frederik Spindler, Jocelyn Falconnet, and Jörg Fröbisch

Acta Palaeontologica Polonica 61 (3), 2016: 597-616 doi:http://dx.doi.org/10.4202/app.00221.2015

This study represents a re-investigation of two historical fossil discoveries, Callibrachion gaudryi (Artinskian of France) and Datheosaurus macrourus (Gzhelian of Poland), that were originally classified as haptodontine-grade sphenacodontians and have been lately treated as nomina dubia. Both taxa are here identified as basal caseasaurs based on their overall proportions as well as dental and osteological characteristics that differentiate them from any other major synapsid subclade. As a result of poor preservation, no distinct autapomorphies can be recognized. However, our detailed investigations of the virtually complete skeletons in the light of recent progress in basal synapsid research allow a novel interpretation of their phylogenetic positions. Datheosaurus might represent an eothyridid or basal caseid. Callibrachion shares some similarities with the more derived North American genus Casea. These new observations on Datheosaurus and Callibrachion provide new insights into the early diversification of caseasaurs, reflecting an evolutionary stage that lacks spatulate teeth and broadened phalanges that are typical for other caseid species. Along with Eocasea, the former ghost lineage to the Late Pennsylvanian origin of Caseasauria is further closed. For the first time, the presence of basal caseasaurs in Europe is documented.

Key words: Synapsida, Caseasauria, Carboniferous, Permian, Autun Basin, France, Intra-Sudetic Basin, Poland.

Frederik Spindler [mail@ frederik-spindler.de], Institut für Geologie, Technische Universität Bergakademie Freiberg, Bernhard von Cotta-Straße 2, 09599 Freiberg, Germany. Jocelyn Falconnet [falconnet@mnhn.fr], Sorbonne Universités CR2P, CNRS-MNHN-UPMC, Département Histoire de la Terre, Muséum National d'Histoire Naturelle, CP 38, 57 rue Cuvier, 75005 Paris, France. Jörg Fröbisch [Joerg.Froebisch@mfn-berlin.de], Museum für Naturkunde Berlin, Leibniz-Institut für Evolutions- und Biodiversitätsforschung, Invalidenstraße 43, 10115 Berlin, Germany; Institut für Biologie, Humboldt-Universität zu Berlin, Invalidenstraße 110, 10115 Berlin, Germany. 
This is an open-access article distributed under the terms of the Creative Commons

Attribution License (for details please see creativecommons.org), which permits unrestricted use, distribution, and reproduction in any medium, provided the original author and source are credited.

For Full text $(1,190.9 \mathrm{kB})$ 